\title{
Deepening Learning through Learning-by-Inventing
}

\author{
Mikko Apiola \\ University of Helsinki, \\ Department of Computer \\ Science, Helsinki, \\ Finland
}

mikko.apiola@helsinki.fi

\author{
Matti Tedre \\ Stockholm University, \\ Department of Computer and \\ Systems Sciences, Kista, \\ Sweden
}

matti.tedre@acm.org

\section{Executive Summary}

It has been shown that deep approaches to learning, intrinsic motivation, and self-regulated learning have strong positive effects on learning. How those pedagogical theories can be integrated in computing curricula is, however, still lacking empirically grounded analyses. In a more general level, it has been widely acknowledged that in tertiary-level computing education there is a desperate need for more creativity and innovation-friendly instructional approaches.

While the use of, for example, problem-based instructional approaches into computing education is increasing, their penetration into computing pedagogy is still shallow. In many contexts of higher computing education, teaching still follows a fixed set of instructional lectures, a fixed set of short-term learning objectives, and a fixed set of predetermined take-home exercises, followed by a pen-and-paper exam. A typical way to teach software development in higher computing education is to utilize industry-standard project management principles in a project, which aims for efficient and risk-free production of software which meets the demands of a customer or a client. As an alternative to the typical conventions, this study investigated students' learning in a learning environment that explicitly focused on inventing and creativity. In other words, this study integrated, in a robotics-based programming class, a method of learning-by-inventing and studied its qualitative effects on students' learning through 144 interviews.

Five findings were related with learning theories: changes in students' problem management cycle, problem-rich learning environment, conceptions of the nature of computing, extension of deep and surface approaches to problem solving and management, and the use of robotics to facilitate deep learning strategies. Our analysis suggests that a combination of an open learning environment, robotics as the learning tool, and learning-by-inventing provides a conducive envi-

Material published as part of this publication, either on-line or in print, is copyrighted by the Informing Science Institute. Permission to make digital or paper copy of part or all of these works for personal or classroom use is granted without fee provided that the copies are not made or distributed for profit or commercial advantage AND that copies 1) bear this notice in full and 2) give the full citation on the first page. It is permissible to abstract these works so long as credit is given. To copy in all other cases or to republish or to post on a server or to redistribute to lists requires specific permission and payment of a fee. Contact Publisher@InformingScience.org to request redistribution permission. ronment for deep learning strategies, intrinsic motivation, and self-regulated learning, which are prerequisite conditions for creativity and inventing.

Keywords: learning-by-inventing, robotics, learning strategies, creativity, intrinsic motivation, problem-based learning. 


\section{Introduction}

There is a plethora of well-justified categorizations for learning objectives in higher education. One of those categorizations is based on the intended levels of understanding (Biggs, 1979). Learning objectives range from ones that are narrowly defined and easily measured - such as learning of factual knowledge and certain specific skills - to ones that are broadly defined and difficult to measure - such as adoption of a deep approach to learning, improvement of activating and self-regulatory learning skills, learning of reflection and self-reflection skills, and development of creativity (Entwistle, 2007).

While the use of, for example, problem-based instructional approaches into computing education is increasing, their penetration into computing pedagogy is still shallow (O'Grady, 2012), and a typical way to teach software development in higher computing education is to utilize industrystandard project management principles in a project, which aims for efficient and risk-free production of software that meets the demands of a customer or a client (Baker, Navarro, \& van der Hoek, 2003).

The learning environment presented in this study was targeted towards undergraduate computer science students. The environment was designed from the viewpoint of creativity research, which states that creativity requires the simultaneous presence of three broad components: intrinsic motivation, a cognitive process of idea generation and idea evaluation, and domain relevant skills (Csikszentmihalyi, 1996). The learning environment aimed at supporting intrinsic motivation and facilitating a process of idea generation and evaluation. The idea generation and evaluation process was facilitated by new peer-to-peer and peer-to-teacher classroom interaction styles, and by granting students control over all aspects of their own learning, including setting their own learning objectives. The learning environment utilized LEGOßMindstorms robots as a platform for students' work.

A practical description of the learning environment, as well as the teachers', researchers', and students' positive experiences have been reported previously (Apiola, Lattu, \& Pasanen, 2012). This study extends the previous results on students' learning in this creativity-supporting learning environment by looking at students' learning more deeply. In this study, students' learning is investigated by analyzing multiple sources of data through classical theoretical constructs that involve the concepts of intrinsic motivation, creativity, and students' learning.

For example, whilst there is an impressive array of research (see Trigwell, Prosser, \& Waterhouse, 1999) on deep approaches to learning - starting from the original distinction by Marton and Säljö (1976) - its embodiments in modern creativity-supporting collaborative learning environments, as well as its implications to the design of such novel learning environments, are not completely understood. It has been argued, for example, that the classic deep approach to learning may prove to be too restricted to conceptualize collaborative, problem-based learning, in the sense that it has an individualistic focus (Lonka, Olkinuora, \& Mäkinen, 2004), and that in the future it might be necessary to have finer distinctions among deep approaches with a more or less individualistic focus (Entwistle \& Entwistle, 2003). Support for deep approaches to learning is considered to be a key component of efficient learning in multiple contexts of education.

On the one hand, the lack of understanding of learning approaches and other related concepts in creativity-supporting learning environments and, on the other hand, the abundance of competing theories on learning approaches and motivation make the analysis and design of modern problembased learning environments a daunting task. What is the significance of pedagogical ideas-such as intrinsic motivation, problem discovery, creative problem solving, and threshold concepts - in analyzing students' learning in modern learning environments, and how can they be easily adapted in the design of learning environments supportive of efficient learning approaches? 
This study investigated students' learning approaches in an experimental course, where learning of advanced programming and other computing topics were taught to undergraduate students by providing an open learning environment supportive of intrinsic motivation, problem discovery, and creative problem solving, and by utilizing LEGO®Mindstorms robots as the central vehicle for learning (see Apiola et al., 2012). In that particular pedagogical setting, students bring their own ideas of problems into the learning environment. The environment is not designed for providing problems but for supporting problem discovery and problem solving. The aims of the learning environment design included support for intrinsic motivation, risk-taking, and deep processing of problems in contrast to producing error-free textbook solutions.

The aims of this research study were to describe students' approaches to learning in this specific learning environment of computing education and to analyze those findings through a number of central theories of learning. In previous research, learning approaches have been frequently connected with conceptions of learning, motivation, and students' learning orientations, and thus, the research data was analyzed from these viewpoints, too. The central questions that guided this study were the following: 1) "Which kinds of learning approaches do students adopt in a creativity-supporting learning environment?", and 2) "Which factors of the learning environment support, and which undermine specific choices between learning approaches?"

\section{Learning Theories}

SAL (Students' Approaches to Learning), and SRL (Self-Regulated Learning) are two dominant research tracks on student learning (Lonka et al., 2004). SRL is based on ideas from North American research, while SAL is based on European research (Lonka et al., 2004). The distinction between deep and surface approaches to learning belongs to the SAL track, it was first presented in the mid-1970s (Marton \& Säljö, 1976), and it has since been followed by a broad range of research. The SAL models have been criticized for oversimplifying learning, while the SRL models have been criticized for being too complicated to be of practical value for educators or educational researchers (Biggs, 2001).

\section{Students' Approaches to Learning (SAL)}

The deep approach to learning can be described as a knowledge-transforming approach, while the surface approach can be described as an information-reproducing approach. It has been shown that deep approaches to learning produce clearly better outcomes than surface approaches do (Marton \& Säljö, 1976). The same student may adopt different learning approaches in different learning tasks (Richardson, 2005) and may switch between approaches also within one study task (Laurillard, 2005).

A student's approach to studying (deep versus surface approach learning) is formed in an interaction process with the learning environment (Marton \& Säljö, 1976). It has been shown that a student's approach to learning is influenced by the student's general conception of learning (Marton, 2005; Marton, Beaty, \& Dall'Alba, 1993; Van Rossum \& Schenk, 1984), the student's conception of the specific learning task, and the student's conception of what is required of him or her (Marton \& Säljö, 1976). It has also been shown that intrinsic motivation generated by a nondemanding and supportive environment is related to deep processing, while extrinsic motivation generated by increased ego-involvement and threat to self-esteem is related to surface processing (Fransson, 1977). Deep and surface approaches to learning have been corroborated by a number of studies (Marton, 2005) and confirmed in many topics of study, such as in problem solving and engineering (Laurillard, 2005). 
This study analyzed students' approaches to learning through students' conceptions of four things: learning in general, the specific learning tasks they were given, what is required of them, and openness of their learning environment.

\section{Self-Regulated Learning (SRL)}

A conceptual framework of self-regulated learning describes self-regulation in learning through four dimensions: cognition, motivation/affect, behavior, and context (Pintrich, 2004). According to the SRL framework, self-regulation in each of these dimensions follows a temporal sequence of planning and goal setting, monitoring, control, and reaction and reflection. Although the phases are described as temporally ordered, there is no strong evidence of the order, and different phases can occur simultaneously and dynamically; for example, goals and plans can be updated based on feedback from control processes (Pintrich, 2004).

Regulation of cognition represents activities and strategies of students for planning, monitoring, and regulating their cognition (Pintrich, 2004). Planning activities include setting specific cognitive goals and activating prior cognitive and metacognitive knowledge. Cognitive monitoring and control include activities to adapt and change cognition, including memory, learning, reasoning, problem-solving, and thinking strategies. Regulation of motivation includes regulation of beliefs, self-efficacy, perceptions of task difficulty, and task value beliefs, and the utilization of different coping strategies to deal with negative affects such as fear and anxiety. Regulation of behavior includes planning and management of time and effort; including making schedules and allocating time, help-seeking behavior, and capability to control effort and persistence in low-value, boring tasks. Regulation of context refers to efforts to control or regulate tasks and the context of the learning environment. Regulation of context is often restricted by the learning environment. However, in some student-centered classrooms students are encouraged to assume more control, for example, by designing their own learning tasks (Pintrich, 2004). In this study the SRL framework was operationalized by looking at students' reports on coping strategies, metacognitive knowledge, positive and negative affects, and time and effort regulation.

\section{Intrinsic and Extrinsic Motivation}

It has been argued that deep learning requires intrinsic motivation (Fransson, 1977; Marton, 2005), which is a type of motivation where a learner performs activities because he or she considers those activities to be interesting (Amabile, 1987; Ryan \& Deci, 2000a, 2000b). On the contrary, an extrinsically motivated learner performs activities primarily due to external rewards or other goals extrinsic to the learning activity itself. Under test conditions, tasks which increased ego-involvement and which were perceived as threatening to self-esteem generated extrinsic motivation, which, in turn, resulted in surface approaches to learning. By contrast, a supportive and non-demanding learning environment was found to be intrinsically motivating and supportive of deep approaches to learning (Fransson, 1977).

Extrinsic rewards, such as positive evaluations or other rewards prior to performance, seem to create extrinsic motivation (Amabile, 1987; Amabile \& Collins, 1999). On the other hand, if a task is constrained or controlled, it results in reduced autonomy and, thus, reduced intrinsic motivation (Amabile \& Collins, 1999). The perceived level of autonomy and freedom are related to higher levels of intrinsic motivation, where, for example, competition for prizes for "best" outputs restricts intrinsic motivation and creativity (Amabile \& Collins, 1999). The self-determination theory (SDT, see: Ryan \& Deci, 2000a, 2000b) argues that intrinsic motivation can be supported by supporting its three forming factors: autonomy, competence, and relatedness. This study operationalized the SDT concepts by looking at students' reports on their level of autonomy, their feelings of competence, and their reports on collaborational (relatedness) aspects of their study work. 


\section{Conceptions of Learning and Intellectual Development}

Research on conceptions of learning originated from the assumption that a student's perception of a learning task reflects his or her past experiences of similar situations, and thus mirrors the differences in a preconceived idea about what it takes to learn (Marton, 2005). Six qualitatively different conceptions of learning have been identified (Marton et al., 1993). Learning can be seen as increasing the quantity of information, as memorizing, as acquisition of facts and methods, as abstraction of meaning, as an interpretive process aimed at understanding reality, and as changing as a person (Marton et al., 1993). Similar conceptions have been confirmed by a number of research studies worldwide (Richardson, 1999).

Educational researchers have proposed various 'hierarchies' of learning (e.g., Anderson et al., 2001; Bloom, Englehart, Furst, Hill, \& Krathwohl, 1956). It has been argued, although not well studied by longitudinal studies, that different conceptions of learning may represent a developmental hierarchy. In the research literature that argument has been supported by comments of informants who mentioned a process of transition between different conceptions (Marton, 2005). The argument is also supported by the similarity between conceptions of learning and Perry's (1970) model of students' intellectual development, which was based on a longitudinal study. Another study found a strong correlation between students' conceptions of learning and students' approaches to learning (Van Rossum \& Schenk, 1984).

In addition to students' general conception of learning, research studies have confirmed that situation-specific conception about learning affects students' approaches to learning (Marton \& Säljö, 1976). Those studies have yielded fairly clear-cut results indicating that the type of testing affects students' approach to learning, which is often called the "backwash effect" (Marton \& Säljö, 1976; Biggs \& Tang, 2011). Students adopt an approach based on their expectations of how they will be tested (Marton \& Säljö, 1976). In the context of problem solving, students who concentrated more on what is expected of them were more likely to adopt surface approaches to learning (Laurillard, 2005). This study analyzed students' conceptions of intellectual development through the six conceptions of learning described by Marton et al. (1993), as well as through their notions of the backwash effect (students focus on what they think they will be tested on).

\section{Learning Orientations}

If a student has a general tendency to behave in a certain manner (such as adopting a deep or surface approach), that tendency may be viewed as a general property of a learner. Such tendencies related to learning are theorized as learning orientations, motivational orientations, or sometimes as learning styles (Lonka et al., 2004). Orientations may provide explanations for why certain students regard certain types of courses (for instance, practical courses) as the most relevant. Orientations as indicators of the basic meaning of studies essentially influence students' study goals and the way they plan, organize, and approach their studies and different learning tasks (Lonka et al., 2004).

One study categorized students' general orientations towards studying into three dimensions: utilizing, internalizing, and achieving (Biggs, 1979). The utilizing orientation resonates with surface approaches to learning, and it is characterized by extrinsic motivation in terms of avoiding failure, minimum effort, and syllabus-boundedness. The internalizing orientation resonates with deep approaches to learning, and it is intrinsically motivated and syllabus-free (student studies beyond the requirements and beyond the topic). The achieving orientation revolves around winning, and it utilizes a systematic approach for gaining highest possible grades using both deep and surface approaches, whenever appropriate (Biggs, 1979). In one study (Ylijoki, 2000), one main disciplinary "tribe" was identified within computer science students. That "tribe" was described as professionally or industrially oriented students who emphasize hard expertise and respect for prag- 
matic skills. That orientation was seen to be influenced by an institutional moral order and culture (Ylijoki, 2000). This study looked at students' learning orientations through students' reports on their failure-avoidance, adherence to syllabus, amount of effort, and emphasis of achievement.

Table 1 summarizes the theoretical constructs introduced above through which the research data was viewed.

\begin{tabular}{|c|c|c|c|c|c|}
\hline SAL & \multicolumn{2}{|c|}{$\begin{array}{l}\text { Learning in general } \\
\text { Specific learning tasks } \\
\text { What is required of self } \\
\text { Openness of the LE }\end{array}$} & SRL & \multicolumn{2}{|c|}{$\begin{array}{l}\text { Coping strategies } \\
\text { Metacognitive knowledge } \\
\text { Positive and negative affect } \\
\text { Time and effort regulation }\end{array}$} \\
\hline \multirow[t]{2}{*}{ 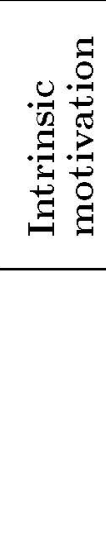 } & \multicolumn{2}{|c|}{$\begin{array}{l}\text { Level of autonomy } \\
\text { Level of competence } \\
\text { Reports of collaborational } \\
\text { aspects }\end{array}$} & 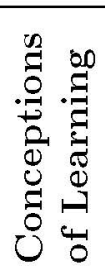 & \multicolumn{2}{|c|}{$\begin{array}{l}\text { Six conceptions described } \\
\text { in (Marton et al., 1993) } \\
\text { Notions of backwash effect }\end{array}$} \\
\hline & 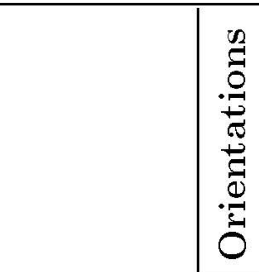 & \multicolumn{3}{|c|}{$\begin{array}{l}\text { Failure avoidance } \\
\text { Adherence to syllabus } \\
\text { Amount of Effort } \\
\text { Emphasis on achievement }\end{array}$} & \\
\hline
\end{tabular}

Table 1: Theoretical constructs for analyzing the interview data

\section{Learning-by-Inventing (LBI) Environment}

The development of the Learning-by-Inventing (LBI) Environment started from a vision of a learning environment for master's level students of computer science, where students, motivated by topics and projects of their own interest, could advance their studies by freely engaging in their own learning by working with various platforms, mobile phones, game consoles, gadgets, and robotics kits of their preferred choice. The vision included promotion of creativity, motivation, inventing, and deep learning through supporting a sense of freedom from restrictions, combined with hard work, fun, play, idea generation, and exploration.

The LBI environment was designed to support creativity, inventing (Csikszentmihalyi, 1996; Sternberg \& Lubart, 1999), and deep learning (Marton \& Säljö, 1976). Support of creativity involved the simultaneous overlap of three broad components: certain kinds of cognitive processes (persistent process of idea generation and evaluation (Jackson \& Shaw, 2006) and deep learning (Marton \& Säljö, 1976)), intrinsic motivation (Amabile, 1987; Ryan \& Deci, 2000a, 2000b, 2001), and domain relevant skills (Amabile, 1983; Csikszentmihalyi, 1996). Constructionism is a support theory for working with LEGOßMindstorms (Papert \& Harel, 1991). Thus, LBI was designed to offer maximal support for the components of intrinsic motivation (competence, autonomy, relatedness), domain-relevant skills of creativity, creative processes (persistent process involving idea generation and evaluation), and constructionism (Apiola et al., 2012).

In practice, in LBI there was no teaching in the traditional sense, but sessions were arranged for discussing problems brought in by the students, for presentations and discussion of students' work, and for idea generation by utilizing a combination of different creativity methods, plays, and open workshops. For example, in the $3+$ method (Lavonen \& Meisalo, 2009), students were divided into groups and set in circles, where everyone in turn presented an idea regarding their project. The next student then had to present three positive things about that idea and after that 
give critique in a positive form. In other experiments, students prepared all their ideas and possible solutions in posters, which were in turn presented and explored by students of other groups. The leading idea behind all sessions was to create a creativity-enhancing, psychologically safe environment for generation and evaluation of ideas regarding the project work.

In LBI students were given maximum autonomy in all phases of their project work, without controlling evaluations. Students were not presented with topics to choose from, but instead they were encouraged and supported to come up with project ideas that they were interested in. This means that students could participate in setting their own learning objectives, learning tasks, and other parameters of the learning environment. The environment was designed to support risktaking and deep processing of problems in contrast to error-free textbook solutions. The domainrelevant skills could be controlled by allowing only skilled students to enter the course. Table 2 presents the implementation of the LBI approach with six course sessions. (For a more thorough description of the LBI, see Apiola et al., 2012).

\begin{tabular}{|c||l|}
\hline$\#$ & Short description \\
\hline 1. & $\begin{array}{l}\text { Information and instructions. } \\
\text { Distribution of robotics kits. }\end{array}$ \\
\hline 2. & $\begin{array}{l}\text { Short lecture on creativity methods. } \\
\text { Divide students into groups. } \\
\text { Ideation exercises with the 3+ (Lavonen \& Meisalo, 2009) method. }\end{array}$ \\
\hline 3. & $\begin{array}{l}\text { Divide students into groups. Continue on creative working } \\
\text { methods. Prepare posters. Use open space workshop (Harrison, 2008). }\end{array}$ \\
\hline 4. & $\begin{array}{l}\text { Generate ideas using creativity methods in one large group. } \\
\text { Discuss the phase and ideas of each groups project. } \\
\text { Use open space workshop (Harrison, 2008). }\end{array}$ \\
\hline 5. & $\begin{array}{l}\text { Generate ideas using creativity methods in one large group. } \\
\text { Discuss the phase and ideas of each groups project. } \\
\text { Use open space workshop (Harrison, 2008). }\end{array}$ \\
\hline 6. & $\begin{array}{l}\text { Final demonstrations. } \\
\text { Every group presents their final project. }\end{array}$ \\
\hline
\end{tabular}

Table 2: Example Learning Sessions in LBI (Apiola et al., 2012)

LBI has similarities to pedagogical approaches such as Problem Based Learning (PBL), Project Based Learning, and Progressive Inquiry. Problem Based Learning emerged from medical education and it offers a widely used model for learning by solving real-world problems (Hmelo-Silver, 2004; Jonassen, 2000). Progressive Inquiry implements scientists' methods to learning (Hakkarainen, 2003), while Project Based Learning unifies these two (Barron et al., 1998) and is applied in science disciplines where learning goals include research methods. The common denominator between these approaches is the changed role of the teacher from an instructor to a facilitator. The approaches also use realistic, open-ended cases and project goals, and stress collaboration between students.

In LBI, creative problem solving was emphasized at the cost of realistic open-ended cases and project goals. Instead of giving rigorous models to minimize risks or failures (such as the procedures of TRIZ (Fulbright, 2011; Tesheng, 2010)), in LBI students were encouraged to take risks and try something new for them. In LBI, students also set their own tasks and discovered their own problems instead of solving problems that teachers give to them. LBI did not encourage only certain types of problems (such as "realistic," or "pragmatic," or "real-world" problems), but instead welcomed all possible problems related to computer science, based on students' own preferences. The notion of theory Y climate assumes that students learn best if they are given freedom 
and room to use their own judgment (Biggs \& Tang, 2011, pp. 39-45; McGregor, 1960). LBI, PBL, and other student-centered pedagogies are well aligned with the theory Y climate.

\section{Methodology}

This study aimed at exploring students' approaches to learning in a new type of a technology-rich creativity-supporting environment at the Department of Computer Science of the University of Helsinki. The theoretical lens for the study was combined from five complementary accounts of learning. The focus of this study was one course, given twice. One of the challenges was that in this study the context of research and the phenomenon itself (learning outcomes and learning environment) were irrevocably intertwined. Those characteristics led this study to be designed as a case study. The methodology literature advocates the use of the case study strategy when the aim is in-depth exploration of, e.g., an educational program (Creswell, 2009, p. 13), when the metaquestion is "what can be learned from a single case?" (cf. Randolph, 2008, p. 53), and "when the boundaries between phenomenon and context are not clearly evident" (Yin, 2003, p. 13). Furthermore, the case study strategy is very well suited for education research: standard literature on the case study strategy commonly uses educational programs as an example (Stake, 1995, ch.10).

Of the various accounts of the case study strategy, this study adopted the procedures described by Creswell (2007, pp. 74-75). The first step of Creswell's procedure-establishing the appropriateness of the case study strategy - was concluded (see above). Second, the case was bounded to a single, focused case with a limited longitudinal dimension. The third step in Creswell's procedure is concerned with data collection. Data collection in case studies is strongly linked to the aims and objectives of research, while methodology literature commonly encourages participant observation and interviews (Richards \& Morse, 2013, p. 77). Furthermore, it is proposed that several types of data collection should be employed, giving multiple perspectives to the case (Creswell, 2007; Yin, 2003). Therefore, this study used three different data collection methods to collect three sets of data: semi-structured student interviews (data set A), observation notes made by the researchers during and after each learning session (data set B), and students' study transcripts (data set C).

Sampling for interview data was a comprehensive sample, and it consisted of 72 initial interviews and 72 concluding interviews. All dropped-out students were reached for the concluding interviews, too. The interviews were semi-structured, and in the initial interviews students were asked to broadly describe their studies, including their personal interests. In the concluding interviews students were asked to describe, in detail, their learning process throughout the course. The interview protocol was tested with two randomly selected computer science students before the actual interviews. Interviews were tape-recorded and transcribed, and for the purposes of this article, quotes were translated to English by the authors.

The fourth step in Creswell's case study procedure is concerned with data analysis (Creswell, 2007, p. 75). As the aims of this study are exploratory and as answering the research questions requires rich descriptions, qualitative holistic analysis strategy (Creswell, 2007) was employed. Following the guidelines described by Stake (1995), we started with relatively uncontested data, looking for the theoretical constructs described in the Learning Theories section of this article. For example, if a student said that he/she tried to anticipate what constitutes "good performance" in the final grading, we marked that down as an instance of the backwash effect. Data saturation point was met roughly halfway the interview data after which no new theoretical constructs were encountered. However, as some theoretical constructs described in the Learning Theories section were not encountered at all, the full data set was analyzed. A number of phenomena outside the theoretical constructs were also identified: those are described in the following section. The same procedure was done on data set B (observation notes). Data set C (transcripts) was analyzed by 
looking at students' phase of studies, grade point averages (GPA), and course preferences (previous courses taken).

At the second level of analysis, the various instances of each theoretical construct and newly identified phenomenon were analyzed for contextual similarities and closeness to other theoretical constructs. That is, when we encountered variations of, for instance, backwash effect (see the Conceptions of Learning and Intellectual Development section of this article) in the interview data, we compared them with other interviews where backwash effect was found, with our observation notes, and with study transcripts. We looked at what other theoretical concepts and similarities those interviews, notes, and transcripts shared, as well as in which aspects they differed and conflicted with each other. However, the output of qualitative analysis is not statistical descriptions but rich descriptions. In this study those descriptions link the data with theoretical constructs. Those descriptions are outlined in the following section.

The final step in Creswell's procedure, the interpretive phase, looks at the meanings found in data. We connected our findings with the theoretical literature, proposed answers to our research questions, related our findings with other research studies on technology-rich learning environments, and constructed a number of lessons-learned from this case.

\section{Results}

Most theoretical constructs described in the section "Learning Theories" of this article manifested in various, rich forms in the interviews and observation notes. The next section below discusses students' disciplinary views, intrinsic and extrinsic motivation, and their theoretical and practical orientations. The section following that discusses students' reports on deep and surface approaches to learning in relation to their problem-solving strategies. That section also relates students' problem management approaches with their concepts of self-regulation. The last section below discusses students' conceptions of learning in the LBI context of learning.

\section{Student Population and Example End Products}

The course that this study evaluated was given twice. The rates of enrolled, active, and passed students at the first round was 36 enrolled, 25 active, and 18 passed; for the second round the rates were and 36 enrolled, 28 active, and 20 passed. A total of 38 students completed the course, with a total of 34 students dropping out. The dropout rate (47\%) is normal in this context, where each semester students enroll in many different courses and complete some, but not all, of those courses. The attendees in the first round ranged from first-year students to postgraduate students with an average of 4.2 years of study. The population in the second round ranged from second year students to a sixteenth year student (average 5.6 years of study). The average ages were 25.8 for the first round, and 23.0 for the second round (see Table 3).

\begin{tabular}{|c|c|c|}
\hline & Course 1 & Course 2 \\
\hline Enrolled in the course & 36 & 36 \\
Active in the course & 25 & 28 \\
Passed the course & 18 & 20 \\
\hline Average age & 25.8 & 23.0 \\
Average year of studies & 4.2 & 5.6 \\
\hline
\end{tabular}

Table 3: Course statistics for the first and second iteration of the course 


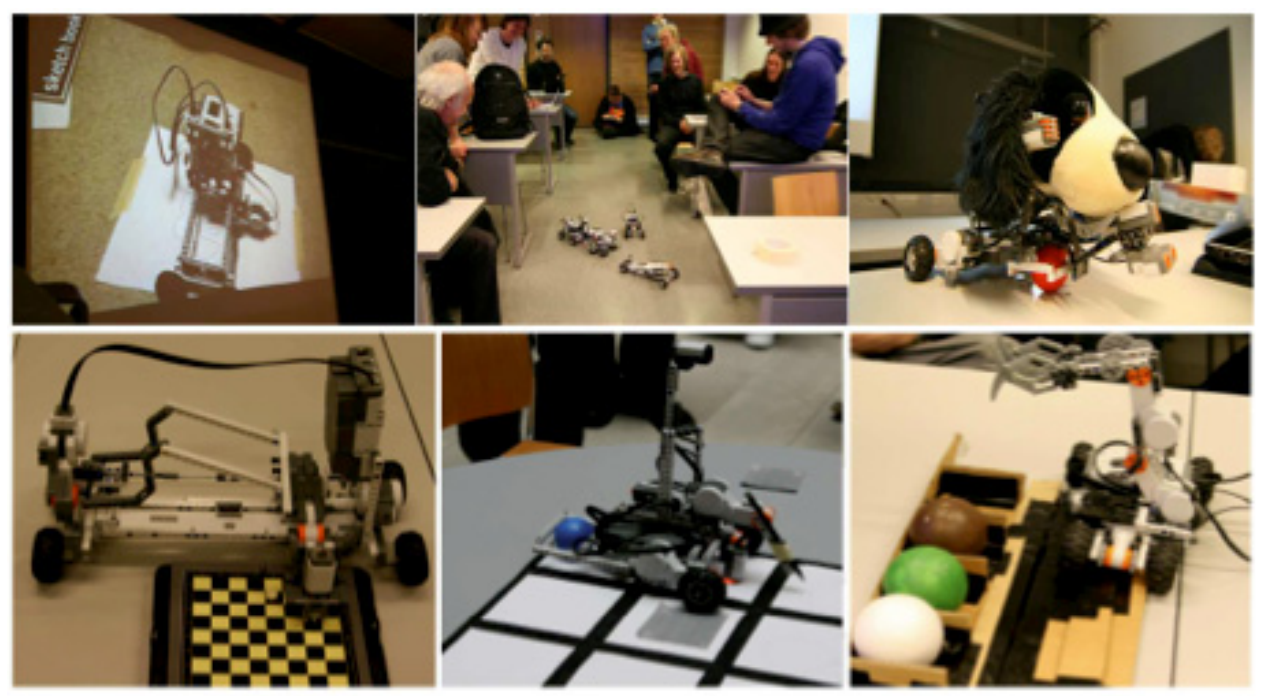

Figure 1: Example Student Projects

Figure 1 shows examples of the students' work. The robot in the upper left corner is a drawer, in the second picture students are playing with various implementations of robot cars, which are remote-controlled by mobile phones and laptop computers. The third robot makes observations about the surrounding world. On the second row, there is a checkers-playing robot, a tic-tac-toeplaying robot, and a robot for simulating the work of sorting algorithms: the robot sorts the balls according to their color. There were a great number of different kinds of other projects too. The students' work was not graded (only pass/fail), as evaluation has been shown to restrict intrinsic motivation and creativity (Amabile, 1987).

\section{Study Orientations (General)}

The first broad theme that arose from the interview data was students' topic orientations among the various computing topics. Concerning their current studies and plans, students' answers indicated orientations towards three main categories: theoretical and scientific topics (such as algorithms, mathematics, physics, and theory of computing), pragmatic topics (such as software engineering and interaction design), and applied topics with interest towards arts, humanities, and social sciences. The categories were not distinct, and many students were unsure about their orientation and were enrolled in different courses in order to find topics of their liking. Some students had a clear view of their orientation, while some students showed interest towards topics across the three categories.

Interviews revealed a combination of extrinsic and intrinsic motivations. Most students reported an extrinsic motivational component in their studies, such as growing as a professional and obtaining qualifications for the labor market. The intrinsic component involved interest in the actual study topics and working on one's own extra-curricular projects. Students' motivational orientations were typically combinations of those two continua. The following paragraphs describe the most common combinations in the data.

The pragmatically oriented, extrinsically motivated student focused on hands-on engineering topics, often had high extrinsic motivation for gaining a formal qualification, and had low intrinsic motivation for studies: “Well, I finished my Bachelor's studies in December and now I'm desperately trying to get a M.Sc. [...] Not likely to happen [...] These studies are kind of basic knowledge like data structures and software processes and some weird methodologies [...] Now when I 
leave and check out some jobs, I'm not gonna be able to really do anything —I just know some things [...] so I hope that I get some work with that paper."

The second common combination of students' orientations was the pragmatically oriented, extrinsically and intrinsically motivated student. Those students were often working in the IT industry, and although they were interested in the topics, they considered themselves to be too skilled to gain much from their studies. Those students were primarily interested in getting a degree by using their existing skill set. Many of them planned their curricular route and study approaches for minimum time to graduation.

The third common combination of orientations of students was the theoretically or scientifically oriented student with mostly intrinsic motivation. Those students had a high interest towards the subject matter, and most of them wished to gain research skills and develop themselves as researchers. Many of those students aimed at postgraduate studies: "Of course I try to get the master's degree [...] I sort of burn for, if I were good enough, for research career [...] I think I have started to emphasize theory grinding and choose those courses [...] I'm interested in their purity from practical baggage that comes with some unexplained bureaucracy-stuff unrelated to computer science". Every student with high interest in the theoretical tradition had high intrinsic motivation.

The fourth common combination of orientations of students was the pragmatically oriented student with mostly intrinsic motivation. Those students typically had high interest in the subject matter of their studies. They did projects of their own interests, and they explored and studied topics beyond the syllabus. In addition to high intrinsic motivation, those students also sometimes mentioned getting a job with a reasonable salary at some point of their life.

\section{Approaches to problem solving and problem discovery}

Characteristics of both deep and surface approaches to learning arose from the research data, which confirmed that both approaches were adopted in the LBI environment, too. Examples of statements that indicated deep approaches were numerous - for example, "it was like, constantly learning through mistakes, you make a mistake and then have to correct it ...we had something ready, and then we started ... we built and wrote program codes and tried all variants on how it could work ... what was central in the whole process was, that it [the right solutions and good ideas] did not come easily ... all the time there was these open matters, which you had to think about and learn more ...for example in the last weekend from Thursday to Tuesday we started to tune the movements and motions of the robot to gain more accuracy, we thought and tested various different solutions, and finally combined with the light sensor we made measurements of the signal and tried some signal correction algorithms, but still could not gain data with enough precision." The emphasis on wanting to understand more, and the interest in learning more even if it takes a lot of time, strongly suggests a deep learning approach.

Examples of surface approaches to learning were also present. Students' responses that indicated surface approaches were of many kinds, but often in those responses students approached the problem with an intention to find a solution in the Internet or by asking their peers for help. In those responses students had no intention to understand and solve the problem themselves. For example, one student stated, "With the practice I was irked at the stage when . . how would you say ... It was like, in principle, problems that you know someone has already solved. But you didn't, like, find anything helpful in the net. A way to solve it. Then I, well, asked for help, and, umm, I had a structural problem. I mean I couldn't get it [the Lego structure] like . . attached to this base tightly".

In many cases situation-specific intrinsic motivation towards this course was obvious. In those cases students put enormous effort and time to the project, they used their own money to buy ad- 
ditional parts, had fun and explained flow-experiences, and made thorough investigations on connecting the device to other consoles and devices. In those cases all phases of project work were driven by intrinsic motivation. On the other hand, there were students whose orientations were mainly extrinsic: to gain study credits with the least work possible.

The cycle of work in the surface approach mainly involved applying students' previous knowledge to solve a previously identified problem. In the cases where that method failed, students attempted to find a working solution, using the Internet, for instance. The failing of that method often led to the generation of negative emotions, such as frustration. In the deep approach, when faced with a challenging problem, the student aimed at exploring other solutions, then moved on to making experiments, exploration, and prototyping - a learning process, which after persistence, eventually seemed to lead to a solution (which can either be knowledge which based on the project strategy may be updated, or a working solution to the original problem), and positive emotions, such as flow experiences.

\section{Problem discovery and solving cycle}

Because the LBI environment did not provide students problems to solve, students themselves had to find and select the problems they wanted to work on. Many students enjoyed the problem discovery process: "It's learning in so many ways, that you don't only learn to build with Legos, but you come across problems that are just really impossible to predict and really impossible to foresee before you're standing in front of the problem. Those [new problems] just sneak on your way. Those are probably the biggest reward from this course."

In the problem discovery process the challenges included, for example, how to circumscribe the problem, how to update the task's problem space, and how to continuously evaluate the suitability of one's problem solving strategy to the task. Self-regulatory skills played a very important role in overcoming these challenges. Another challenge concerned the difficulty of problems. The interviews indicated that it was hard for students to predict the amount of work that would be involved in their selected problems. Generally speaking, students' selected problems turned out to be more complex than they looked like on the first impression. On the one hand, this aspect of LBI facilitated deep learning, because it pushed most learners into the zone of proximal development (ZPD) (Vygotsky, 1978). On the other hand, too difficult problems were demotivating in those cases where students were not able to update their problem spaces accordingly. Choosing a suitable level of difficulty is a common challenge in learning environment design, but creativity researchers have suggested that too much challenge is better for learning than too little challenge is (Moneta \& Csikszentmihalyi, 1999).

Once each student had selected a problem to solve, students started to work on their problems. At that point they did the first choice between deep and surface learning approaches. Solving too easy problem does not require deep approaches to learning, and thus a proper amount of challenge is one important prerequisite.

\section{Problem management approach}

The interview data revealed a continuum of general project management processes employed by students. Those problem management approaches formed a continuum from serialistic to exploratory. Serialistic problem management approach attempted to treat the problem as a linear set of steps to be followed, somewhat similar to the waterfall model in software engineering: "We thought of some ideas and then we decided what we are going to do. We thought a little bit about how we are going to develop the thing. After that we started building the robot. When the robot was ready we started coding it. We wanted something that would interact with its environment, but that turned out to be difficult. " 
In contrast, the exploratory problem management approach was a more organic, investigative, and iterative process. Students made prototypes, and they flexibly jumped back and forth between designs, prototypes, and models. They compared solutions and made experiments: “...well I started [the project] from a concrete viewpoint: I took the LEGO bricks in my hand and started to build all sorts of different things... I thought that well, let's try this kind of thing: I will test this sensor and then I will test that other sensor and measure how much torque this motor has and things like that, I built small prototypes and wrote program codes for them. A program like this does something funny and then I realized that this is not at all what I want, and then you just build on it and at some point you have like one thousand lines of code and you think that this subject is not at all going to work and it is not what I want."

\begin{tabular}{|l|l|}
\hline Serialistic Approach & Exploratory Approach \\
\hline Linear and iterative & Cyclic and free-moving \\
\hline Serialistic & Holistic \\
\hline Risk-averse & Open to risks \\
\hline Industrial by nature & Hobbyist by nature \\
\hline Closed-ended & Open-ended \\
\hline Outcome-oriented & Experiment-oriented \\
\hline
\end{tabular}

Table 4: Characteristics of the Two Identified Problem Management Approaches

Table 4 presents some characteristics of the two problem management approaches identified in our interviews. Students' project management approaches probably influenced their problem discovery and selection, as well as their problem solving approach. As the LBI environment relied on open problem discovery, selection, and problem-solving, in this case the exploratory approach arguably worked better than the serialistic approach did. The two problem management approaches had clear parallels with deep and surface approaches to learning. Although the serialistic approach may be well suited for the industry, it does not seem to be well suited for learning, as it did not encourage one to enter the ZPD (Vygotsky, 1978). There again, the exploratory approach pushed the learner away from pre-determined models and solutions into developing of one's own problems, approaches, models, and solutions.

The data did not show students' reason for selecting problem management approaches. One reason might be related to the backwash effect: students chose approaches that they thought would be rewarded (and which other courses have rewarded). Otherwise, traces of backwash effect were not found in the data.

\section{Conceptions of Learning}

\section{General conceptions of learning}

Another broad theme arising from the interview data was students' conceptions of how a learning environment in computing should look. The working methods and new class interaction in the LBI were new to all students, who were used to traditional teaching arrangements. One student noted: "I really had to take my time in getting used to the idea that this [kind of course with these kind of working methods] is really going to take place at our department [...] I guess I am stuck with old views about how teaching should be arranged [...]".

One student who considered the openness and problem discovery process in the LBI environment to be a positive thing stated:

"[...] and then you are suddenly surrounded with such problems which seriously are just impossible to predict and impossible to see beforehand, before the situation is actually in front of you [...] Those problems just somehow insidiously appear from somewhere, totally 
out of the blue [...] those sudden problems are perhaps the biggest yield, which I gained from this course. [...] That you see, that things are not what you thought them to be, but instead they are completely different even though you had imagined the whole process in advance, like: here is the problem [...] but when you see it in front of you, you notice that you had planned it completely wrong, and then you think, how on Earth can this thing work this way. I have not seen anything like this in any other course of computer science before. [...]"

The quotes above suggest an expansion of the students' conception of a "proper" computer science learning environment. Students who considered openness to be a negative thing came up with various suggestions for improving the learning environment: fixed exercise sets, technical guidance, and strict deadlines. One student stated: "Next time, I recommend that you provide those strict deadlines and phases of work in terms of planning, designing, coding and building, and testing. I also recommend that you provide clearer instructions for building the robots, topics to choose from, and also you should get the more advanced type of sensors with better accuracy".

\section{Situation-specific conceptions of learning}

The next theme that arose from the data was concerned with situation-specific conceptions of learning. The LBI environment neither restricted the types of problems nor provided support for specific types of problems, but all kind of problems were welcome. Still, some students seemed to consider the course to be a hands-on, time-intensive engineering course. Indeed, many students chose engineering-oriented topics. But with some students, their situation-specific conception restricted the student from choosing a more theoretically oriented topic. Some theoretically oriented student dropped out because they did not consider that the course offered a platform for problems of their preference.

An example statement from a dropped-out theoretically oriented student: "I am more interested in those things related to algorithms and such [...] from this course, I was left with a feeling that even if you wanted to do some basic stuff, it will soon become complicated and require a high workload. [...] So as development ideas, I suggest [...] as for example in the Artificial Intelligence-course I liked, when the Roomba-robots were used and the project topic was restricted to write pattern recognition or image manipulation algorithms and such".

In the first implementation of the LBI, we indeed observed that dropped out students $(n=21)$ had a significantly higher GPA than students who completed the course (GPA 3.49 versus GPA 3.00) $p<.05[\mathrm{~F}(1,38)=5.312, p=.027]$. Higher GPA students in the course were also more theoretically/scientifically oriented towards studies. In the second implementation of the LBI the situation was the opposite, and the students who completed the course had a significantly higher GPA than students who dropped out (GPA 3.25 versus GPA 2.72), $p<.06[\mathrm{~F}(1,33)=3.956, p=.055]$. This implies that students' situation-specific conception was different between the first and second rounds of implementation of the LBI. This hypothesis is supported by the increased amount of theoretically oriented project topics on the second round of LBI.

\section{Discussion}

This study asked two research questions: "Which kinds of learning approaches do students adopt in a creativity-supporting learning environment?" and "Which factors of the learning environment support, and which undermine specific choices between learning approaches?". This study found a number of interesting insights into students' approaches to learning with robotics as a learning tool, as well as into LBI as a pedagogical vehicle.

Firstly, students reported that the learning-by-inventing approach was able to relax their problem management cycle in a way that enabled students to deeply inquire into specific sub-problems as well as holistically engage in problem control. Secondly, students' reports suggested that the LBI 
approach was able to provide a learning environment that was rich with problems that could excite a variety of students with problems of their own liking. That approach stood in contrast to the previous practices where teacher gave either a list of homework problems to solve or a large assignment at the beginning of the semester.

Thirdly, students' reports imply that their intrinsic motivation was connected with their conceptions about the disciplinary nature of computing as well as their conceptions about effective learning environments. Fourthly, the free choice and management of problems had a number of consequences. Our initial concern was that in a very free environment students would choose problems that they already knew how to solve, which would lead to little or no learning. The concern did not materialize broadly, and if faced with a too difficult problem, students were able to quickly ease the problem parameters or find a different problem to work on. Thus, deep and surface approaches extended from learning to problem solving and problem management. Fifthly, the robots offered a powerful trigger for motivation, as well as a platform for a broad variety of problems that students presented.

In the broader scheme of things, the challenges of computing have, for the past 65 years, grown more complex every year. Computing continues to pervade other fields of life, which continues to diversify the problem types posed to computing professionals. At the same time, the complexity of problems with which computing professionals have to cope is growing. Our future professionals need to cope with a wide variety of problems and must be able to look at problems in innovative ways and from multiple perspectives. Educators in computing fields are already able to train students to work with basic types of problems - now we need to broaden our focus to creativity and real-life complexity. Pedagogical approaches, such as learning by doing, provide a good basis for training problem solving in computing education. The approach analyzed by this paper, an approach we call learning-by-inventing (LBI), extends learning-by-doing by facilitating learning of creativity and inventing through supporting new approaches to problem solving, and new approaches to learning in computer science.

\section{References}

Amabile, T. M. (1983). Social psychology of creativity: A componential conceptualization. Journal of Personality and Social Psychology, 45(2), 357-376.

Amabile, T. M. (1987). The motivation to be creative. In S. Isaksen (Ed.), Frontiers of creativity research: Beyond the basics. Buffalo, NY: Bearly Limited.

Amabile, T. M., \& Collins, M. (1999). Motivation and creativity. In R. R. Sternberg \& R. Lubart (Eds.), Handbook of creativity. Cambridge, UK: Cambridge University Press.

Anderson, L. W., Krathwohl, D. R., Airasian, P. W., Cruikshank, K. A., Mayer, R. E., Pintrich, P. R., et al. (2001). A taxonomy for learning, teaching, and assessing: A revision of Bloom's taxonomy of educational objectives. New York, NY, USA: Addison Wesley Longman.

Apiola, M., Lattu, M., \& Pasanen, T. A. (2012). Creativity-supporting learning environment-CSLE. ACM Transactions on Computing Education, 12(3), 11:1-11:25.

Baker, A., Navarro, E. O., \& van der Hoek, A. (2003). An experimental card game for teaching software engineering processes. Journal of Systems and Software,75(1-2), 3-16.

Barron, B. J. S., Schwartz, D. L., Vye, N. J., Moore, A., Petrosino, A., Zech, L., et al. (1998). Doing with understanding: Lessons from research on problem- and project-based learning. The Journal of the Learning Sciences, 7(3\&4), 271-311.

Biggs, J. (1979). Individual differences in study processes and the quality of learning outcomes. Higher Education, 8(4), 381-394. 
Biggs, J. (2001). Enhancing learning: A matter of style or approach? In R. Sternberg \& L. Zhang (Eds.), Perspectives on thinking, learning, and cognitive styles (pp. 77-102). Mahwah: Lawrence Erlbaum.

Biggs, J., \& Tang, C. (2011). Teaching for quality learning at university: What the student does (4th ed.) Berkshire, England: McGraw-Hill Education.

Bloom, B .S., Englehart, M. D., Furst, E. J., Hill, W. H., \& Krathwohl, D. R. (1956). Taxonomy of educational objectives: The classification of educational goals. Handbook I: Cognitive domain. New York, NY, USA: Longmans.

Creswell, J. W. (2007). Qualitative inquiry and research design: Choosing among five approaches (3rd ed.) Thousand Oaks, CA, USA: Sage Publications.

Creswell, J. W. (2009). Research design: Qualitative, quantitative, and mixed methods approaches (3rd ed.) Thousand Oaks, CA, USA: Sage Publications.

Csikszentmihalyi, M. (1996). Creativity: Flow and the psychology of discovery and invention. New York, NY, USA: Harper Perennial.

Entwistle, N. (2007). Research into student learning and university teaching. In N. Entwistle \& P. Tomlinson (Eds.), Student learning and university teaching. Psychological aspects of educationCurrent trends, pp. 1-18. The British Psychological Society Monograph Series II.

Entwistle, N., \& Entwistle, D. (2003). Preparing for examinations: The interplay of memorizing and understanding, and the development of knowledge objects. Higher Education Research \& Development, 22(1), 19-41.

Fransson, A. (1977). On qualitative differences in learning: IV-Effects of intrinsic motivation and extrinsic test anxiety on process and outcome. British Journal of Educational Psychology, 47(3), 244-257.

Fulbright, R. (2011). I-TRIZ: Anyone can innovate on demand. International Journal of Innovation Science, 3(2), 41-54.

Hakkarainen, K. (2003). Emergence of progressive-inquiry culture in computer-supported collaborative learning. Learning Environments Research, 6(2), 199-220.

Harrison, O. (2008). Open space technology: A user's guide. San Francisco, CA: Berrett- Koehler.

Hmelo-Silver, C. E. (2004). Problem-based learning: What and how do students learn? Educational Psychology Review, 16(3), 235-266.

Jackson, N., \& Shaw, M. (2006). Developing subject perspectives on creativity in higher education. In N. Jackson, M. Oliver, M. Shaw \& J. Wisdom (Eds.), Developing creativity in higher education. An imaginative curriculum. London, UK: Routledge.

Jonassen, D. H. (2000). Toward a design theory of problem solving. Educational Technology Research and Development, 48(4), 63-85.

Laurillard, D. (2005). Styles and approaches in problem-solving. In F. Marton, D. Hounsell, and N. Entwistle (Eds.), The experience of learning: Implications for teaching and studying in higher education (3rd ed.), pp. 126-144. Edinburgh, UK: University of Edinburgh, Centre for Teaching, Learning and Assessment.

Lavonen, J., \& Meisalo, V. (2009). Creative problem solving (Luovan ongelmanratkaisun työtavat). University of Helsinki Teacher Training Materials.

Lonka, K., Olkinuora, E., \& Mäkinen, J. (2004). Aspects and prospects of measuring studying and learning in higher education. Educational Psychology Review, 16, 301-323.

Marton, F. (2005). Approaches to learning. In F. Marton, D. Hounsell \& N. Entwistle (Eds.), The experience of learning: Implications for teaching and studying in higher education (3rd ed.), (pp. 39-58). Edinburgh, UK: University of Edinburgh, Centre for Teaching, Learning and Assessment.

Marton, F., Beaty, E., \& Dall'Alba, G. (1993). Conceptions of learning. International Journal of Educational Research, 19, 277-300. 
Marton, F., \& Säljö, R. (1976). On qualitative differences in learning - 2: Outcome as a function of the learner's conception of the task. British Journal of Educational Psychology, 46(2), 115-127.

McGregor, D. (1960). The human side of enterprise. New York, USA: McGraw-Hill.

Moneta, G. B., \& Csikszentmihalyi, M. (1999). Models of concentration in natural environments: A comparative approach based on streams of experiential data. Social Behavior and Personality: An International Journal, 27(6), 603-637.

O'Grady, M.J. (2012). Practical problem-based learning in computing education. ACM Transactions on Computing Education, 12(3), 10:1-10:16.

Papert, S., \& Harel, I. (1991). Situating constructionism. In S. Papert \& I. Harel (Eds.), Constructionism (pp. 1-11). Norwood, NJ: Ablex Publishing Corporation.

Perry, Jr., W. G. (1970). Forms of intellectual and ethical development in the college years: A scheme. New York, NY, USA: Holt, Rinehart and Winston.

Pintrich, P. (2004). A conceptual framework for assessing motivation and self-regulated learning in college students. Educational Psychology Review, 16, 385-407.

Randolph, J. J. (2008). Multidisciplinary methods in educational technology research and development. Hämeenlinna, Finland: HAMK University of Applied Sciences.

Richards, L. G., \& Morse, J. M. (2013). README FIRST for a user's guide to qualitative methods. Thousand Oaks, CA, USA: Sage Publications.

Richardson, J. T. E. (1999). The concepts and methods of phenomenographic research. Review of Educational Research, 69(1), 53-82.

Richardson, J. T. E. (2005). Students' approaches to learning and teachers' approaches to teaching in higher education. Educational Psychology, 25(6), 673-680.

Ryan, R. M., \& Deci, E. L. (2000a). Intrinsic and extrinsic motivations: Classic definitions and new directions. Contemporary Educational Psychology, 25(1), 54-67.

Ryan, R. M., \& Deci, E. L. (2000b). Self-determination theory and the facilitation of intrinsic motivation, social development, and well-being. American Psychologist, 55(1), 68-78.

Ryan, R. M., \& Deci, E. L. (2001). On happiness and human potentials: A review of research on hedonic and eudaimonic well-being. Annual Review of Psychology, 52, 141-166.

Stake, R. E. (1995). The art of case study research. Thousand Oaks, CA, USA: Sage Publications.

Sternberg, R., \& Lubart, T. (1999). The concept of creativity: Prospects and paradigms. In R. Sternberg \& T. Lubart (Eds.), Handbook of creativity. Cambridge University Press.

Tesheng, L. (2010). Applying TRIZ and AHP to develop innovative design for automated assembly systems. International Journal of Advanced Manufacturing Technology, 46(1-4), 301-313.

Trigwell, K., Prosser, M., \& Waterhouse, F. (1999). Relations between teachers' approaches to teaching and students' approaches to learning. Higher Education, 37(1), 57-70.

Van Rossum, E. J., \& Schenk, S. M. (1984). The relationship between learning conception, study strategy and learning outcome. British Journal of Educational Psychology, 54(1), 73-83.

Vygotsky, L. S. (1978). Mind in society: The development of higher psychological processes. Cambridge, Mass., USA: Harvard University Press.

Yin, R. K. (2003). Case study research: Design and methods (3rd ed.) Thousand Oaks, CA, USA: Sage Publications.

Ylijoki, O.H. (2000). Disciplinary cultures and the moral order of studying - A case-study of four Finnish university departments. Higher Education, 39(3), 339-362. 


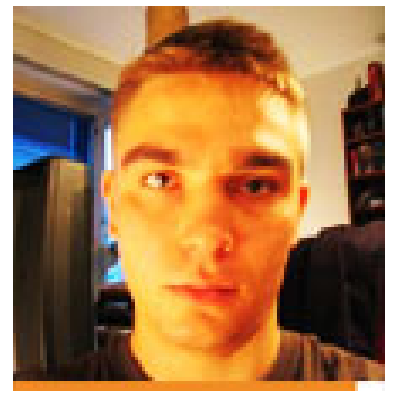

\section{Biographies}

Mikko Apiola is a PhD student at the University of Helsinki, Department of Computer Science, Finland. His research interests include computer science education, and ICT in education. In the past, Mikko has worked as a part-time teacher in the University of Helsinki, Department of Computer Science, and as an assistant lecturer at Tumaini University's Iringa College in Iringa, Tanzania. Mikko has also worked for several years in the IT-industry.

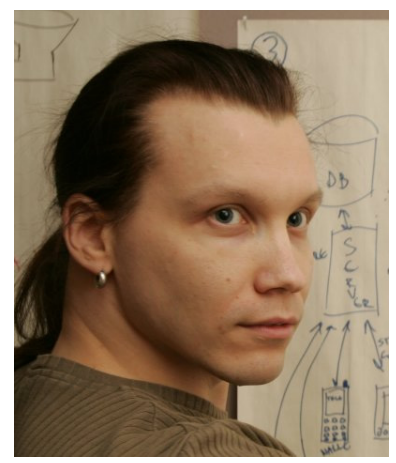

Matti Tedre works with flexible learning and the philosophy of computer science at Stockholm University, Department of Computer and Systems Sciences. His research interests include computer science education, research methods of computer science, social studies of computer science, the philosophy of computer science, and ICT4D (ICT for development). He is also an Adjunct Professor of Informatics and Design at Cape Peninsula University of Technology, South Africa, and an Adjunct Professor of Computer Science at University of Eastern Finland. 